\title{
Photocatalytic Performance of ZnO: Al Films under Different Light Sources
}

\author{
Prashant Pradhan, Juan Carlos Alonso, and Monserrat Bizarro \\ Instituto de Investigaciones en Materiales, Universidad Nacional Autónoma de México, A.P. 70-360, \\ Coyoacán 04510, DF, Mexico \\ Correspondence should be addressed to Monserrat Bizarro, monserrat@iim.unam.mx
}

Received 26 July 2012; Revised 25 August 2012; Accepted 12 September 2012

Academic Editor: Jiaguo Yu

Copyright (C) 2012 Prashant Pradhan et al. This is an open access article distributed under the Creative Commons Attribution License, which permits unrestricted use, distribution, and reproduction in any medium, provided the original work is properly cited.

$\mathrm{ZnO}$ and $\mathrm{Al}$ doped $\mathrm{ZnO}$ films were produced by spray pyrolysis. The films were characterized by X-ray diffraction (XRD), scanning electron microscopy (SEM), UV-vis spectroscopy, and photoluminescence. Their photocatalytic activity was evaluated by the decomposition of the methyl orange dye using different light sources: ultraviolet light, artificial white light, and direct sunlight. The films were also tested under darkness for comparison. The $\mathrm{ZnO}$ films were able to degrade the test pollutant under UV and sunlight in more than a $60 \%$ after 180 min of irradiation and a scarce degradation was obtained using white light. However, the $\mathrm{Al}$ doped $\mathrm{ZnO}$ films presented a very high degradation rate not only under UV and sunlight (100\% degradation), but also under white light (90\% degradation after the same irradiation time). An unexpected high degradation was also obtained in the dark, which indicates that a nonphotonic process is taking place parallel to the photocatalytic process. This can be due to the extra electrons_-provided by the aluminum atoms - that migrate to the surface and produce $\mathrm{O}_{2}{ }^{\circ-}$ radicals favoring the decomposition process even in the dark. The high activity achieved by the $\mathrm{ZnO}$ : Al films under natural conditions can be potentially applied to water treatment processes.

\section{Introduction}

Metal oxide photocatalysts are being considered as an effective alternative to decompose toxic organic pollutants in waste water [1]. $\mathrm{TiO}_{2}$ and $\mathrm{ZnO}$ are two examples of efficient photocatalyst; nevertheless, both of them are activated only under UV light due to their large band gap of $3.2 \mathrm{eV}[2,3]$. The big challenge of the last few years has been to extend the photocatalytic activity of these semiconductors to the visible region of the solar spectrum, since solar energy is the most desired light source for a clean and efficient photocatalytic system. If this goal is achieved, the use of photocatalysts for environmental remediation will be even more important and will contribute to the reduction of the excessive use of nonrenewable energy sources. The principal way to address the problem of extending the spectral range in which the photocatalyst can absorb light has been introducing electrically active dopants in these oxide semiconductors. For the case of photocatalysts in the form of fine powders or nanoparticles, good photocatalytic activity under visible light has been obtained by doping $\mathrm{TiO}_{2}$ with metal or nonmetal atoms like nitrogen, carbon, iron, manganese, and cobalt among others [4-12]. In the case of zinc oxide, which is an alternative photocatalyst to $\mathrm{TiO}_{2}$, with a similar band gap but with lower cost [13], it has been demonstrated that $\mathrm{ZnO}$ powders or nanoparticles doped with atoms such as $\mathrm{Mn}, \mathrm{N}, \mathrm{Fe}, \mathrm{W}, \mathrm{La}$, and $\mathrm{Ag}$ possess also very good photocatalytic properties under visible light [14-20]. For water treatment application the powder and nanoparticles represent a drawback, as further separation steps are needed after the degradation process. This is the motivation to obtain supported $\mathrm{ZnO}$ in the form of thin films or membranes that can be removed easily after the water treatment. For instance, Liu and coworkers synthesized hierarchical $\mathrm{CuO} / \mathrm{ZnO}$ membranes able to degrade different dyes [21]. In a previous work, we demonstrated that aluminum doped zinc oxide in the form of thin film highly increase the photocatalytic activity of pure $\mathrm{ZnO}$ under UV light [22]. As it 
was pointed out in that work, one important advantage of using this material in the form of thin film, instead of fine powders or nanoparticles, is the elimination of filtration and separation steps after the dye removal. In that work, we observed that the activity enhancement under UV light can be due to factors such as the surface structure, the doping concentration, and the electronic distribution. However, it is important to study the mechanisms that allow the activation of the material with lower energy, in order to have an efficient ecological photocatalyst. In the present work we investigated the photocatalytic response, extended to the visible region, of $\mathrm{ZnO}$ : Al films using different illumination sources (sunlight and white light) compared to its activity under UV light. We also report an unexpected activity of the doped samples in the dark. A correlation of the photocatalytic activity with other physical properties, such as the band gap and photoluminescence emission, is explored.

\section{Experimental Setup}

Pure and aluminum doped $\mathrm{ZnO}$ films were deposited by the pneumatic spray pyrolysis technique using a $0.2 \mathrm{M}$ aqueous solution of zinc acetate dihydrate $\left(\mathrm{Zn}\left(\mathrm{CH}_{3} \mathrm{COO}\right)_{2} \cdot 2 \mathrm{H}_{2} \mathrm{O}\right.$, Sigma-Aldrich, 98\%). Aluminum chloride hexahydrate $\left(\mathrm{AlCl}_{3} \cdot 6 \mathrm{H}_{2} \mathrm{O}\right.$, Sigma-Aldrich, 99\%) was added as a source of aluminum, in an $(\mathrm{Al}) /(\mathrm{Zn})$ atomic ratio of 0.25 to the previous solution. The films were grown at a substrate temperature of $500^{\circ} \mathrm{C}$ on pyrex glass substrates of $1 \times 0.5$ inches; two of these substrates were placed in each film deposition and constitute one sample as they were introduced back inside the vial for the photocatalytic tests. The gas and solution flow rates were fixed at $8 \mathrm{~L} / \mathrm{min}$ and $14.6 \mathrm{~mL} / \mathrm{min}$ respectively, as previously determined [22]. Four identical, samples of pure and $\mathrm{Al}$ doped $\mathrm{ZnO}$ were deposited, in order to perform the photocatalytic experiments under different illumination conditions simultaneously. The films were characterized by X-ray diffraction (XRD) (Bruker D8) using the $\mathrm{Cu} \mathrm{K} \alpha_{1}$ wavelength (1.54056 $\AA$ ), scanning electron microscopy (SEM) (Leica Cambridge 400) with an energy dispersed spectroscopy device (EDS) for chemical composition analysis, profilometry (Sloan DekTak IIA), and photoluminescence (SPEX FluoroMax).

The photocatalytic efficiency of the films was evaluated by monitoring the discoloration of a methyl orange (MO) solution (Sigma-Aldrich, $85 \%$ purity) with a concentration of $10^{-5} \mathrm{M}$, at the maximum absorption wavelength using a UV-vis spectrophotometer (Perkin Elmer Lambda 35). Each pair of samples (doped and undoped $\mathrm{ZnO}$ films) was exposed to different illumination sources: (i) ultraviolet light (UV) lamp of $9 \mathrm{~W}$ and emission centered at $380 \mathrm{~nm}$; (ii) direct exposure to sunlight (the experiments were performed in mostly sunny days but regardless the small changes in the weather conditions of Mexico City at the geographical coordinates: $\varphi=19^{\circ} 21^{\prime} \mathrm{N}, \lambda=99^{\circ} 09^{\prime} \mathrm{W}$ ); (iii) artificial white light (WL) of a $9 \mathrm{~W}$ lamp (cool light type) with a broad emission in the visible spectrum from 400 to $650 \mathrm{~nm}$. The fourth pair of samples was kept in the dark as control (the samples were stored in a box and kept in a dark room). The

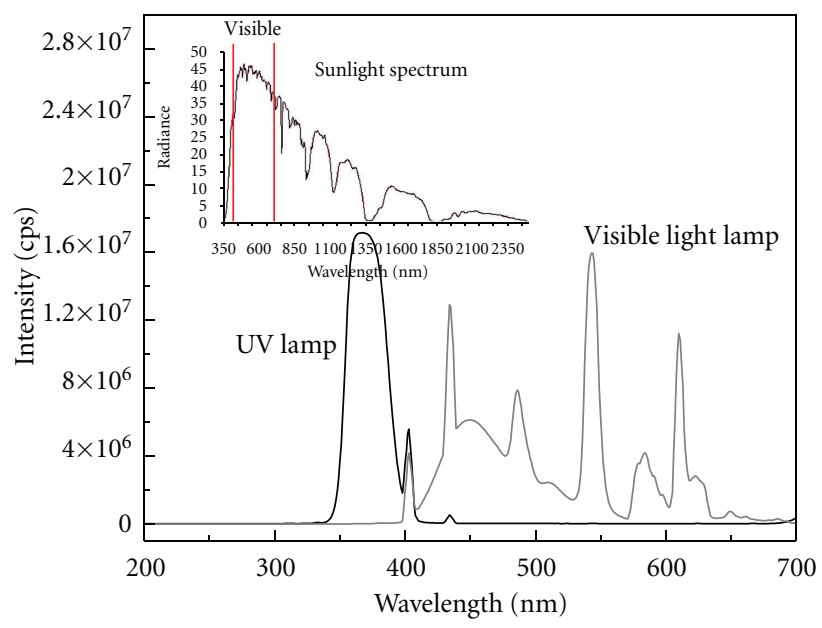

FIGURE 1: Emission spectra of the different illumination sources: (a) ultraviolet light (UV), (b) white light (WL), and (c) sunlight (inset).

emission spectra of the illumination sources were measured with a spectrofluorometer (SPEX FluoroMax) and are shown in Figure 1. The absorption spectra of the methyl orange solution were measured after each 30 minutes of illumination up to 3 hours. The degradation percentage of the dye was obtained with the absorbance maxima ratio of the methyl orange before $\left(A_{0}\right)$ and after $(A)$ an irradiation time, as follows:

$$
\text { Degradation } \%=\left(1-\frac{A}{A_{0}}\right) * 100 \text {. }
$$

\section{Results}

3.1. Microstructure and Composition. The characteristics of pure and $\mathrm{Al}$ doped films were analyzed in detail in a previous work [22]. It was observed that the deposition conditions have a great influence on the morphological characteristics of the films. Particularly, the surface topography is largely modified under certain temperature and flow rates conditions, and it also depends on the aluminum concentration in the precursor solution, as it can be appreciated in the SEM images inserted in Figure 2. It was also observed that the crystal structure was the wurtzite hexagonal phase of $\mathrm{ZnO}$ for all the samples (according to the International Centre for Diffraction Data, ICDD, database file 01-036-1451), with a preferential orientation along the (002) direction that increases with the aluminum concentration (Figure 2). No other phases or compounds were detected. However, the EDS analysis revealed the incorporation of the aluminum into the zinc oxide lattice, which is in a lower proportion than the aluminum added to the solution, as shown in Table 1. In addition, XPS analysis shows (Figure 3 ) that the incorporation of $\mathrm{Al}$ reduces the concentration of $\mathrm{Zn}$ in the $\mathrm{ZnO}$ : $\mathrm{Al}$ films, which is indicative that $\mathrm{Al}$ atoms substitute $\mathrm{Zn}$ atoms in the $\mathrm{ZnO}$ lattice.

The thickness and roughness of the films were measured and their average values are presented in Table 1. As it was said before, the incorporation of aluminum into the $\mathrm{ZnO}$ 
TABLE 1: Composition of the films and their average thickness and roughness.

\begin{tabular}{lcccc}
\hline Sample name & $\mathrm{Al} / \mathrm{Zn}$ in solution $($ at $\%)$ & $\mathrm{Al} / \mathrm{Zn}$ in the film $($ at $\%)$ & Thickness $(\mathrm{nm})$ & 1114 \\
$\mathrm{ZnO}$ & 0 & 0 & 2151 & 65 \\
$\mathrm{ZnO}: \mathrm{Al}$ & 25 & 0.12 & Roughness $(\mathrm{nm})$ \\
\hline
\end{tabular}

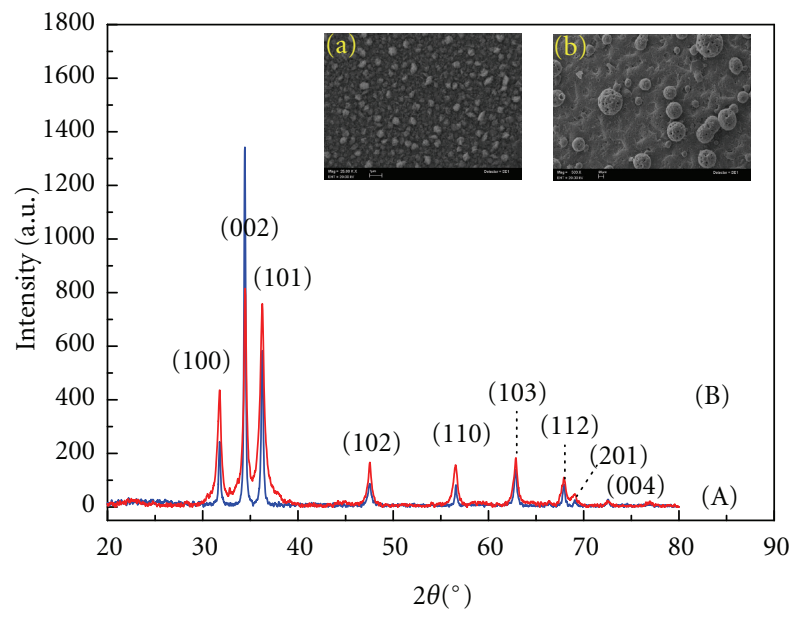

Figure 2: XRD patterns of pure (a) and $\mathrm{Al}$ doped (b) $\mathrm{ZnO}$ films. The insert shows the SEM images of their corresponding surfaces.

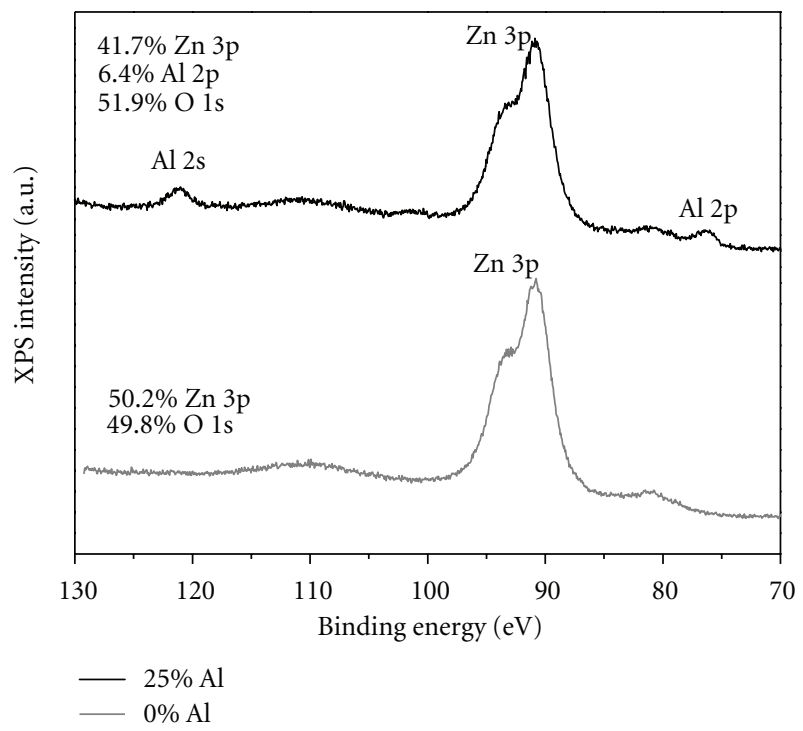

Figure 3: XPS spectra of the pure and $\mathrm{Al}$ doped $\mathrm{ZnO}$ films. The presence of aluminum decreased the concentration of $\mathrm{Zn}$, indicating that $\mathrm{Al}$ is a substitutional impurity.

film produces morphological changes, but also the deposition rate is modified, so different thicknesses are obtained for similar flow rates.

3.2. Photocatalytic Activity. The degradation of the methyl orange solution was measured using the pure and doped $\mathrm{ZnO}$ films under the three mentioned illumination sources. Figure 4(a) shows a picture taken of the different samples exposed to sunlight after 2 hours. It is also shown a control sample without film that was irradiated and measured as well. No degradation of the methyl orange (MO) control sample was observed, but it is clearly seen that the complete discoloration of the dye is achieved faster for the sample doped with $\mathrm{Al}$ than for the pure $\mathrm{ZnO}$ film (Figure 4(b)).

To obtain the kinetics of the reactions, the natural logarithm of the maximum of absorption was obtained for each measurement and plotted as a function of time, as shown in Figure 4(c). The data follow a linear relation indicating a first-order reaction, as established by the LangmuirHinshelwood model [23]. The samples with aluminum showed the highest photocatalytic response. Surprisingly, this response was not only under illumination but also in the dark. Any effect was observed for the pure $\mathrm{ZnO}$ films under artificial white light or darkness; they could degrade the dye only under UV and sunlight. This is evidence that the aluminum impurities modify the original compound. The rates of reaction of every sample were calculated by the slope of the fitted lines in Figure 4(c) and are shown in Figure 4(d), where it is clearly seen that the activity of the doped films is more than 3 times greater than for the pure $\mathrm{ZnO}$ films under UV and sunlight illumination. In addition, a very high activity is observed for the $\mathrm{ZnO}: \mathrm{Al}$ film in the dark. This indicates the existence of an alternative process that degrades the dye without light. This material offers a great alternative to purify water even at latitudes where low sunlight radiation is received.

In order to study the reproducibility and the reusability of the films, a complete set of new samples was fabricated and tested in photocatalysis. The repeated films provided similar results under the same conditions. In addition, the samples that were reused in the photocatalytic tests showed a small diminution of the activity (around 10\%) that was more evident in the pure $\mathrm{ZnO}$ samples.

3.3. Optical Properties. Although the films are relatively thick and their optical transparency is thus, low, their optical transmission spectra were recorded to obtain the absorption coefficient $(\alpha)$ and analyze the optical band gap of the films. To calculate the direct optical band gap of $\mathrm{ZnO}$ and $\mathrm{ZnO}$ : $\mathrm{Al}$ films the Tauc model was used as follows:

$$
\alpha h v=A\left(h v-E_{g}\right)^{n},
$$

where $A$ is a constant, $h$ is Planck's constant, $v$ is the photon frequency, $E_{g}$ is the optical ban gap, and $n=1 / 2$ for direct band gap semiconductors. A plot of $(\alpha h v)^{2}$ against the photon energy $h v$ is shown in Figure 5. The extrapolation of the linear part of the curve to zero gives the value of the optical band gap. The results show that the band gap is slightly higher for the doped films $\left(E_{g}=3.25 \mathrm{eV}\right)$ than for the pure 

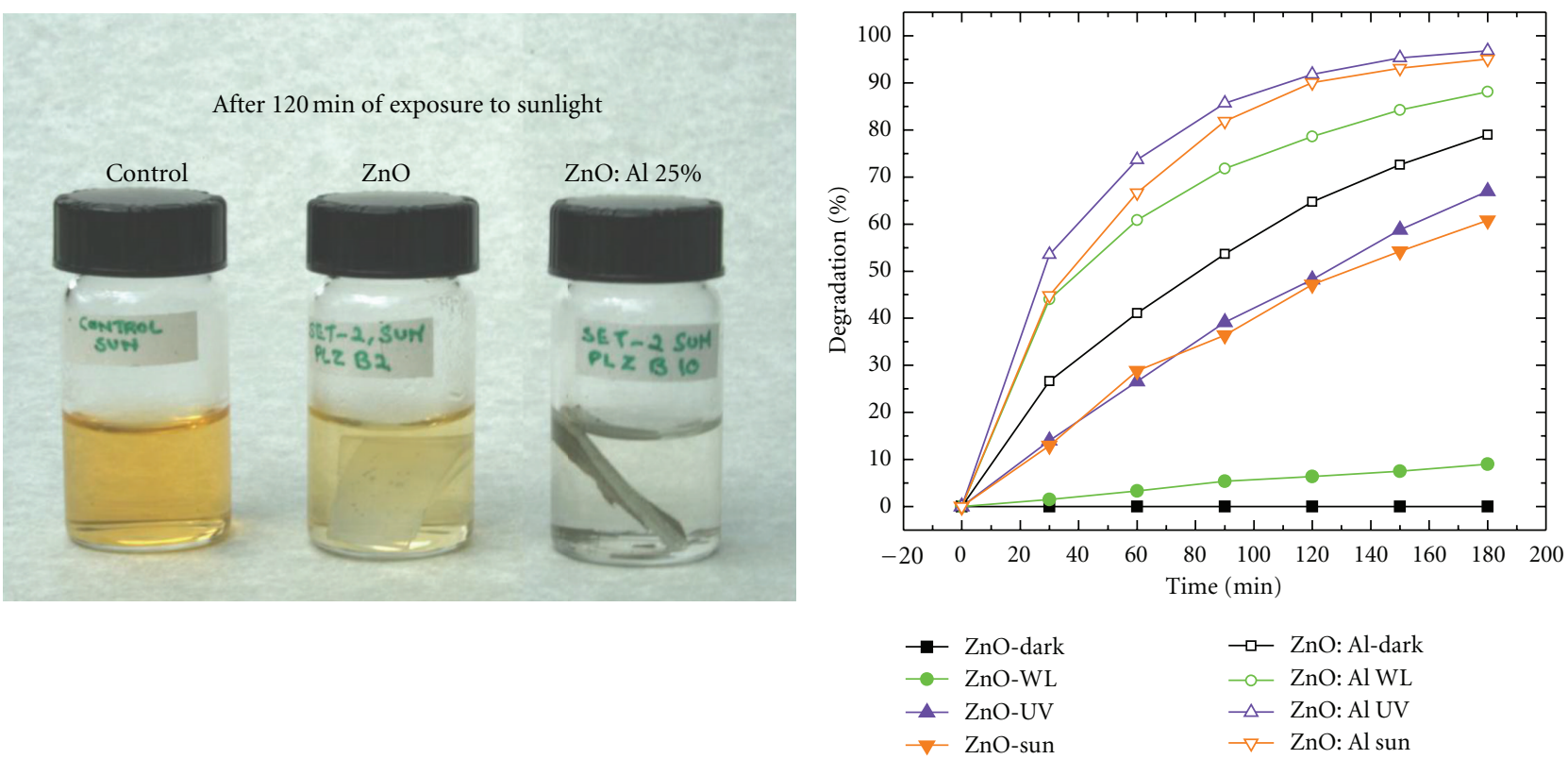

(a)
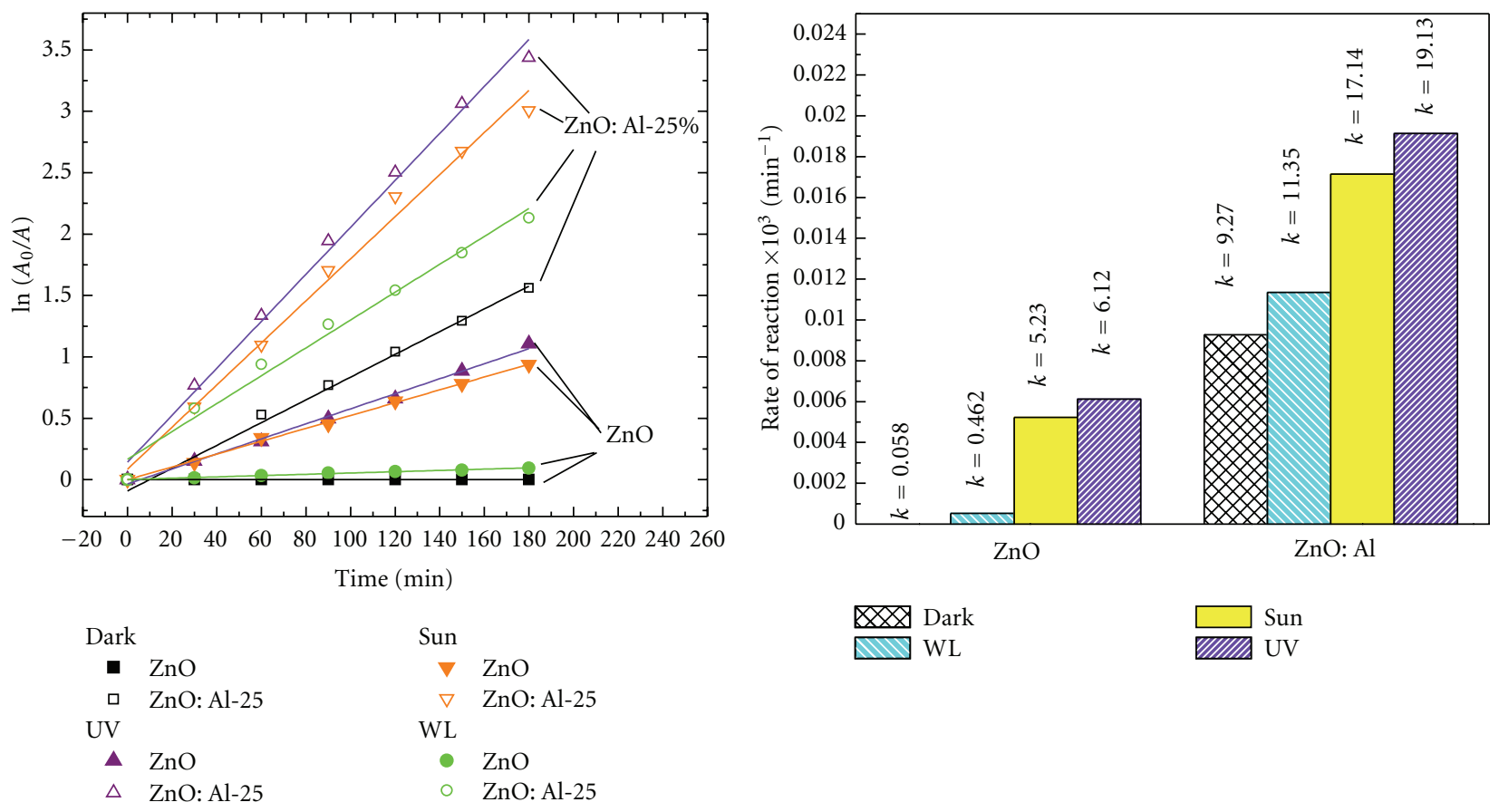

(c)

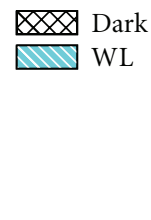

(b)

(d)

FIgURE 4: (a) Picture of the samples after 2 hours of exposure to sunlight. The control sample is the MO dye without film. The other two recipients contain the semiconductor film inside. (b) Degradation percentage and (c) kinetics of reaction of $\mathrm{ZnO}$ (filled symbols) and $\mathrm{ZnO}$ : $\mathrm{Al}$ (open symbols) under different illuminations: dark (black), artificial white light (green), ultraviolet light (purple), and sunlight (orange). (d) Rate of reaction of the $\mathrm{ZnO}$ and $\mathrm{ZnO}$ : $\mathrm{Al}$ films under different illumination sources and darkness for comparison.

$\mathrm{ZnO}$ films $(3.22 \mathrm{eV})$. This increase in the $\mathrm{ZnO}$ band gap when aluminum is introduced is consistent with other works $[24,25]$ and may be due to the occupation of the lowest levels in the conduction band by the electrons of the impurity atoms and produce a direct transition with higher energy $[26,27]$.
The optical band gap values coincide with those obtained by room temperature photoluminescence spectra, shown in Figure 6. The spectra have a narrow peak centered at 383 and $381 \mathrm{~nm}$ (UV emission) for $\mathrm{ZnO}$ and $\mathrm{ZnO}$ : $\mathrm{Al}$, respectively, which correspond to the band to band transitions (of 3.24 and $3.25 \mathrm{eV}$ in each case), and a broad band centered 


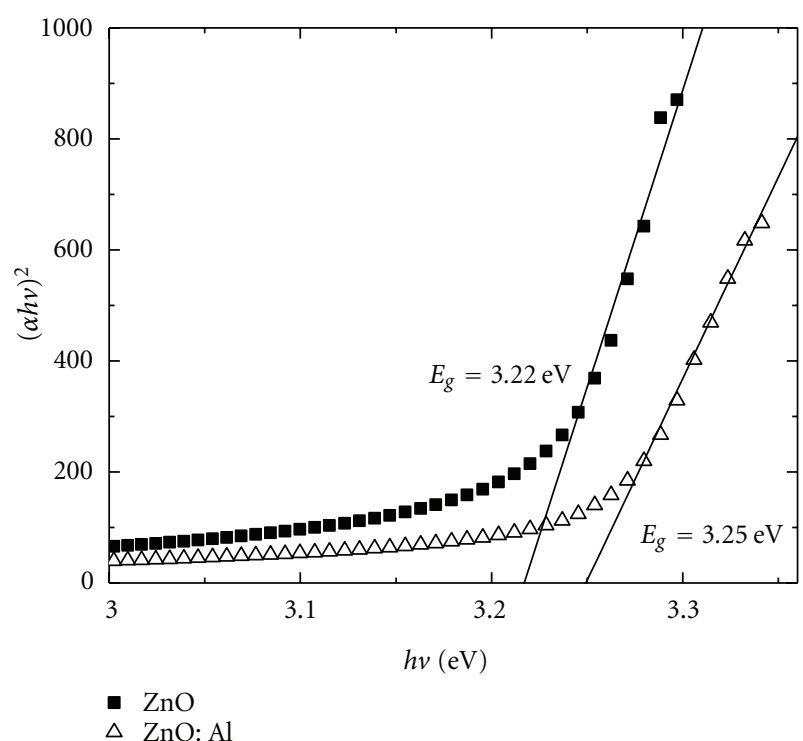

Figure 5: Determination of the band gap of $\mathrm{ZnO}$ and $\mathrm{ZnO}$ : Al films.

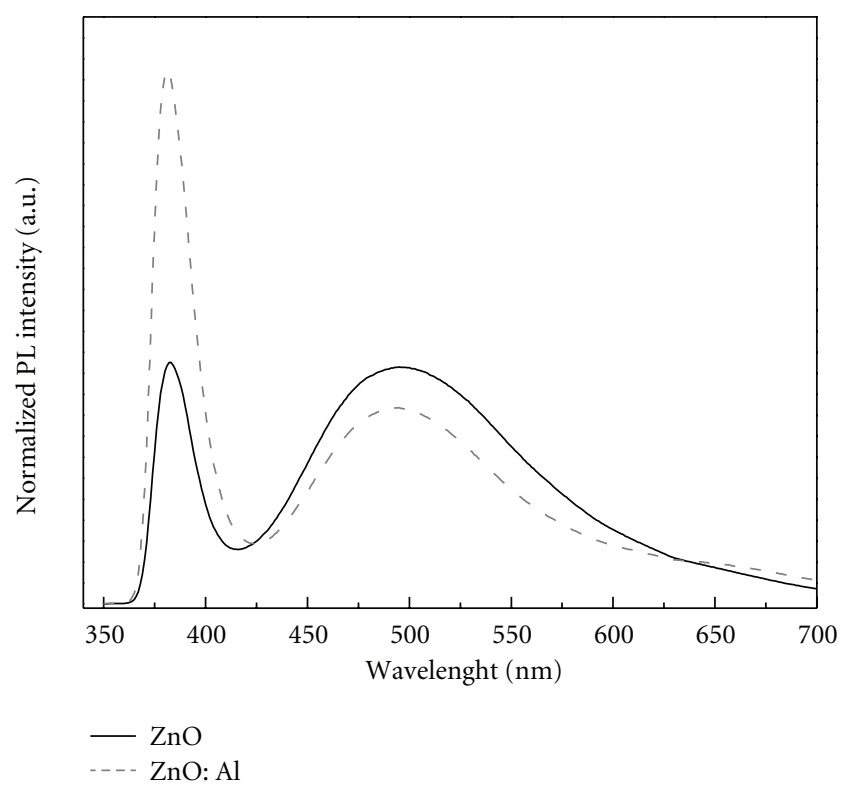

Figure 6: Normalized photoluminescence of $\mathrm{ZnO}$ and $\mathrm{ZnO}: \mathrm{Al}$ films.

around $500 \mathrm{~nm}$ called green emission. The green emission is attributed to structural defects in the crystalline lattice, although the type of defects responsible of this visible emission is not fully understood [28]. For the pure $\mathrm{ZnO}$ film, both peaks have the same intensity, indicating a similar probability of occurrence. However, for the doped film the intensity of the high energy peak increases and the green emission peak decreases. This indicates a higher band to band recombination rate and a diminution of the radiative transitions due to defects. Sharma et al. found that $\mathrm{Al}$ in $\mathrm{ZnO}$ matrix promotes the oxygen diffusion through the $\mathrm{ZnO}$ lattice, leading to the suppression of oxygen vacancies $\left(V_{\mathrm{O}}\right)$
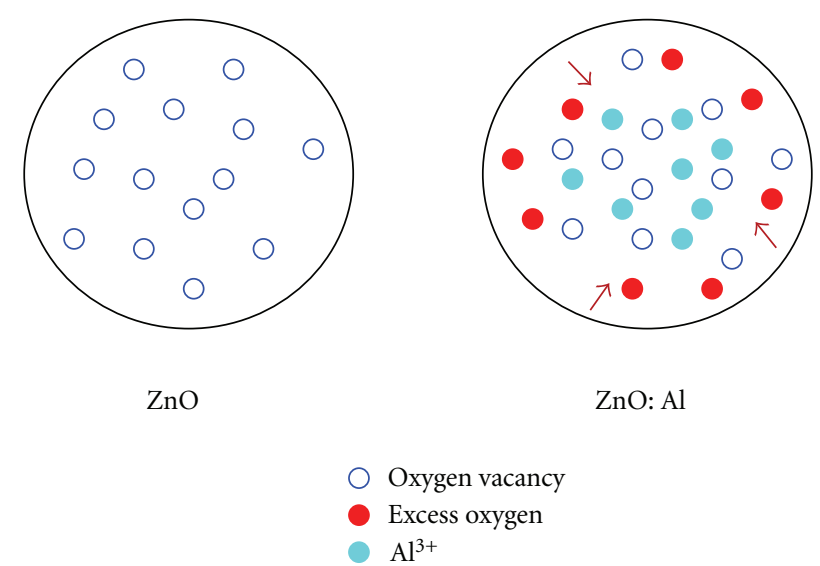

Figure 7: Schematic representation of defects in $\mathrm{ZnO}$ and $\mathrm{ZnO}$ : $\mathrm{Al}$ films. The red arrows indicate the diffusion of excess oxygen to the $\mathrm{ZnO}$ grain due to the presence of $\mathrm{Al}$ atoms.

and the creation of oxygen interstitial $\left(\mathrm{O}_{i}\right)$ defects [29]. The work of Y. Liu et al. also coincides with this idea and they proposed a distribution model of the oxygen vacancies, the excess oxygen and the aluminum atoms in the $\mathrm{ZnO}$ grains that can explain the green and orange luminescence of $\mathrm{ZnO}$ : Al films [28]. Following these ideas, we can say that the incorporation of $\mathrm{Al}$ favors the oxygen diffusion and neutralizes some of the intrinsic oxygen vacancies of $\mathrm{ZnO}$, as represented in Figure 7. This results in the diminution of the visible emission band of the doped samples. Furthermore, Mahmood et al. reported that $\mathrm{O}_{i}$ has a low energy of formation under oxidizing conditions [30], so it is easy to find this type of defect in our films, as they were grown under ambient conditions. However, we consider that the excess oxygen is not in a very large concentration because we do not observe a red shift of the green emission peak. This excess oxygen may be neutralizing some of the $V_{\mathrm{O}}$ inside the grains, but the $V_{\mathrm{O}}$ concentration in our samples may be high, giving only a slight diminution of the intensity of this peak.

The PL study of $\mathrm{ZnO}$ and $\mathrm{ZnO}$ : Al films can help us to understand the photocatalytic activity of the films. First, we can see that the undoped film has already a large amount of structural defects that introduce electronic levels within the band gap. These levels facilitate the electron transport from the valence band to the conduction band and can explain the weak activity under white light illumination. On the other hand, the $\mathrm{Al}$ doped $\mathrm{ZnO}$ films, in addition to the intrinsic defects-such as $V_{\mathrm{O}}$-also have $\mathrm{Al}$ atoms that provide an extra electron, which contributes to the reduction of the $\mathrm{O}_{2}$ dissolved in the aqueous medium and form the superoxide radical $\mathrm{O}_{2}{ }^{--}$, which in turn contribute to the formation of hydrogen peroxide on the semiconductor surface [20]. All these radicals produce the decomposition of the dye. This is the reason for the significant increase of the photocatalytic activity. However, the degradation of the dye without any light in presence of the $\mathrm{ZnO}$ : $\mathrm{Al}$ films could be attributed to high mobility of the extra electrons provided by the $\mathrm{Al}$ atoms, that migrate to the surface of the semiconductor and start the formation of $\mathrm{O}_{2}{ }^{\cdot-}$ radicals (it should be pointed out that 
$\mathrm{ZnO}$ : $\mathrm{Al}$ has been used as transparent conductive oxide due to its high free carrier concentration and mobility $[31,32])$. Considering the change in morphology of the doped films, that present higher roughness and more contact area, the number of reactions that can take place also increases, producing a high discoloration of the dye even without light.

\section{Conclusions}

The present work compared the photocatalytic activity of pure and aluminum doped $\mathrm{ZnO}$ films under white light, sunlight, and UV illumination. ZnO films showed good degradation efficiency under UV and sunlight and barely degraded using white light. However, the $\mathrm{Al}$ doped $\mathrm{ZnO}$ films not only increased three times the photocatalytic activity of $\mathrm{ZnO}$ under UV and sunlight, but also degraded the dye under white light and even in the dark. The degradation of the dye using white light is explained due to the intrinsic defects (such as $V_{\mathrm{O}}$ ) in $\mathrm{ZnO}$ matrix that facilitates the charge transport between bands. This charge transport is enhanced by the aluminum atoms that provide an extra electron, which is able to migrate to the semiconductor surface even without needing a photon. The electron migration can start the formation of radicals that decompose the dye molecules, explaining the unexpected activity without illumination. The photocatalytic ability of the $\mathrm{ZnO}$ : Al films allows the development of a low cost, high efficiency, and environmentally friendly material for water treatment applications using sunlight.

\section{Acknowledgments}

The authors wish to thank Adriana Tejeda, Omar Novelo, and Lázaro Huerta for technical support. M. Bizarro is grateful to the fellowship "For women in science L'OrealUNESCO-AMC 2011." This work was financially supported by DGAPA-UNAM under Projects IN-116109, IA100811, and IB101912.

\section{References}

[1] D. Bahnemann, "Photocatalytic water treatment: solar energy applications," Solar Energy, vol. 77, no. 5, pp. 445-459, 2004.

[2] J.-M. Herrmann, "Heterogeneous photocatalysis: state of the art and present applications," Topics in Catalysis, vol. 34, no. 1-4, pp. 49-65, 2005.

[3] M. R. Hoffmann, S. T. Martin, W. Choi, and D. W. Bahnemann, "Environmental applications of semiconductor photocatalysis," Chemical Reviews, vol. 95, no. 1, pp. 69-96, 1995.

[4] D. Li, H. Haneda, S. Hishita, and N. Ohashi, "Visible-lightdriven nitrogen-doped $\mathrm{TiO} 2$ photocatalysts: effect of nitrogen precursors on their photocatalysis for decomposition of gasphase organic pollutants," Materials Science and Engineering $B$, vol. 117, no. 1, pp. 67-75, 2005.

[5] M. Maeda and T. Yamada, "Photocatalytic activity of metaldoped titanium oxide films prepared by sol-gel process," Journal of Physics, vol. 61, no. 1, article 151, pp. 755-759, 2007.
[6] M. Maeda and T. Watanabe, "Visible light photocatalysis of nitrogen-doped titanium oxide films prepared by plasmaenhanced chemical vapor deposition," Journal of the Electrochemical Society, vol. 153, no. 3, pp. C186-C189, 2006.

[7] D. Noguchi, Y. Kawamata, and T. Nagatomo, "The response of $\mathrm{TiO} 2$ photocatalysts codoped with nitrogen and carbon to visible light," Journal of the Electrochemical Society, vol. 152, no. 9, pp. D124-D129, 2005.

[8] S. Sakthivel and H. Kisch, "Daylight photocatalysis by carbonmodified titanium dioxide," Angewandte Chemie, vol. 42, no. 40, pp. 4908-4911, 2003.

[9] A. Kubacka, M. Fernández-García, and G. Colón, "Nanostructured Ti-M mixed-metal oxides: toward a visible light-driven photocatalyst," Journal of Catalysis, vol. 254, no. 2, pp. 272284, 2008.

[10] J. Yu, H. Yu, C. H. Ao, S. C. Lee, J. C. Yu, and W. Ho, "Preparation, characterization and photocatalytic activity of in situ Fe-doped TiO2 thin films," Thin Solid Films, vol. 496, no. 2, pp. 273-280, 2006.

[11] J. P. Wang, H. C. Yang, and C. T. Hsieh, "Visible-light photodegradation of dye on Co-doped Titania nanotubes prepared by hydrothermal synthesis," International Journal of Photoenergy, vol. 2012, Article ID 206534, 10 pages, 2012.

[12] C. H. Huang, Y. M. Lin, I.-K. Wang, and C. M. Lu, "Photocatalytic activity and characterization of carbon-modified titania for visible-light-active photodegradation of nitrogen oxides," International Journal of Photoenergy, vol. 2012, Article ID 548647, 13 pages, 2012.

[13] O. Mekasuwandumrong, P. Pawinrat, P. Praserthdam, and J. Panpranot, "Effects of synthesis conditions and annealing post-treatment on the photocatalytic activities of $\mathrm{ZnO}$ nanoparticles in the degradation of methylene blue dye," Chemical Engineering Journal, vol. 164, no. 1, pp. 77-84, 2010.

[14] R. Ullah and J. Dutta, "Photocatalytic degradation of organic dyes with manganese-doped $\mathrm{ZnO}$ nanoparticles," Journal of Hazardous Materials, vol. 156, no. 1-3, pp. 194-200, 2008.

[15] H. F. Lin, S. C. Liao, and S. W. Hung, "The dc thermal plasma synthesis of $\mathrm{ZnO}$ nanoparticles for visible-light photocatalyst," Journal of Photochemistry and Photobiology A, vol. 174, no. 1, pp. 82-87, 2005.

[16] D. Li and H. Haneda, "Synthesis of nitrogen-containing $\mathrm{ZnO}$ powders by spray pyrolysis and their visible-light photocatalysis in gas-phase acetaldehyde decomposition," Journal of Photochemistry and Photobiology A, vol. 155, no. 1-3, pp. 171178, 2003.

[17] D. Li and H. Haneda, "Photocatalysis of sprayed nitrogencontaining $\mathrm{Fe} 2 \mathrm{O} 3-\mathrm{ZnO}$ and $\mathrm{WO} 3-\mathrm{ZnO}$ composite powders in gas-phase acetaldehyde decomposition," Journal of Photochemistry and Photobiology A, vol. 160, no. 3, pp. 203-212, 2003.

[18] H. Wang, S. Baek, J. Lee, and S. Lim, "High photocatalytic activity of silver-loaded $\mathrm{ZnO}-\mathrm{SnO} 2$ coupled catalysts," Chemical Engineering Journal, vol. 146, no. 3, pp. 355-361, 2009.

[19] S. Anandan, Y. Ikuma, and V. Murugesan, "Highly active rareearth metal La-doped photocatalysts: fabrication, characterization and their photocatalytic activity," International Journal of Photoenergy, vol. 2012, Article ID 921412, 10 pages, 2012.

[20] T. Parvin, N. Keerthiraj, I. A. Ibrahim, S. Phanichphant, and K. Byrappa, "Photocatalytic degradation of municipal wastewater and brilliant blue dye using hydrothermal synthesized surface-modified silver-doped $\mathrm{ZnO}$ designer particles," International Journal of Photoenergy, vol. 2012, Article ID 670610, 8 pages, 2012. 
[21] Z. Liu, H. Bai, and D. Delai Sun, "Hierarchical $\mathrm{CuO} / \mathrm{ZnO}$ Mambranes for environmental applications under the irradiation of visible light," International Journal of Photoenergy, vol. 2012, Article ID 804840, 11 pages, 2012.

[22] M. Bizarro, "High photocatalytic activity of $\mathrm{ZnO}$ and $\mathrm{ZnO}: \mathrm{Al}$ nanostructured films deposited by spray pyrolysis," Applied Catalysis B, vol. 97, no. 1-2, pp. 198-203, 2010.

[23] H. Al-Ekabi and N. Serpone, "Kinetic studies in heterogeneous photocatalysis. 1. Photocatalytic degradation of chlorinated phenols in aerated aqueous solutions over $\mathrm{TiO} 2$ supported on a glass matrix," Journal of Physical Chemistry, vol. 92, no. 20, pp. 5726-5731, 1988.

[24] S. Mridha and D. Basak, "Aluminium doped $\mathrm{ZnO}$ films: electrical, optical and photoresponse studies," Journal of Physics D, vol. 40, no. 22, pp. 6902-6907, 2007.

[25] F. K. Shan and Y. S. Yu, "Band gap energy of pure and Al-doped $\mathrm{ZnO}$ thin films," Journal of the European Ceramic Society, vol. 24, no. 6, pp. 1869-1872, 2004.

[26] M. Bizarro, A. Sánchez-Arzate, I. Garduño-Wilches, J. C. Alonso, and A. Ortiz, "Synthesis and characterization of $\mathrm{ZnO}$ and $\mathrm{ZnO}: \mathrm{Al}$ by spray pyrolysis with high photocatalytic properties," Catalysis Today, vol. 166, no. 1, pp. 129-134, 2011.

[27] B. E. Sernelius, K. F. Berggren, Z. C. Jin, I. Hamberg, and C. G. Granqvist, "Band-gap tailoring of $\mathrm{ZnO}$ by means of heavy $\mathrm{Al}$ doping," Physical Review B, vol. 37, no. 17, pp. 10244-10248, 1988.

[28] Y. Liu, H. Zhang, X. An et al., "Effect of Al doping on the visible photoluminescence of $\mathrm{ZnO}$ nanofibers," Journal of Alloys and Compounds, vol. 506, no. 2, pp. 772-776, 2010.

[29] B. K. Sharma, N. Khare, and D. Haranath, "Photoluminescence lifetime of Al-doped $\mathrm{ZnO}$ films in visible region," Solid State Communications, vol. 150, no. 47-48, pp. 2341-2345, 2010.

[30] M. A. Mahmood, S. Baruah, and J. Dutta, "Enhanced visible light photocatalysis by manganese doping or rapid crystallization with $\mathrm{ZnO}$ nanoparticles," Materials Chemistry and Physics, vol. 130, pp. 531-535, 2011.

[31] Y. Liu and J. Lian, "Optical and electrical properties of aluminum-doped $\mathrm{ZnO}$ thin films grown by pulsed laser deposition," Applied Surface Science, vol. 253, no. 7, pp. 3727-3730, 2007.

[32] M. Gabás, S. Gota, J. R. Ramos-Barrado et al., "Unraveling the conduction mechanism of Al-doped $\mathrm{ZnO}$ films by valence band soft x-ray photoemission spectroscopy," Applied Physics Letters, vol. 86, no. 4, Article ID Article number042104, pp. 042104-1, 2005. 


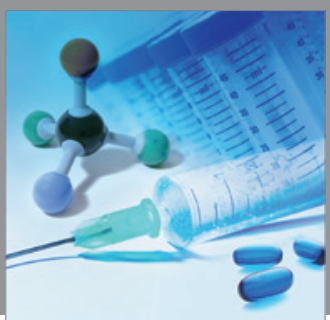

International Journal of

Medicinal Chemistry

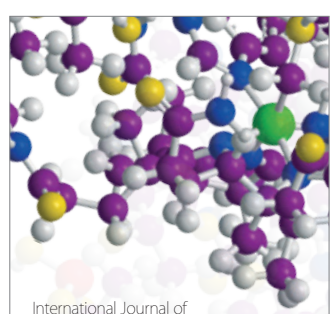

Carbohydrate Chemistry

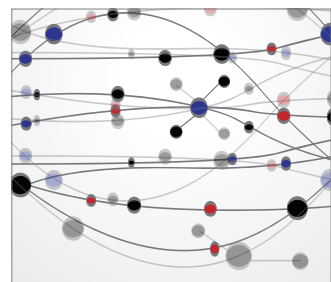

The Scientific World Journal
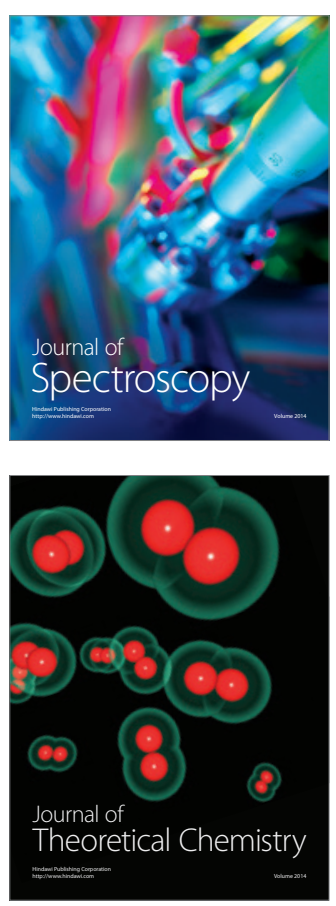
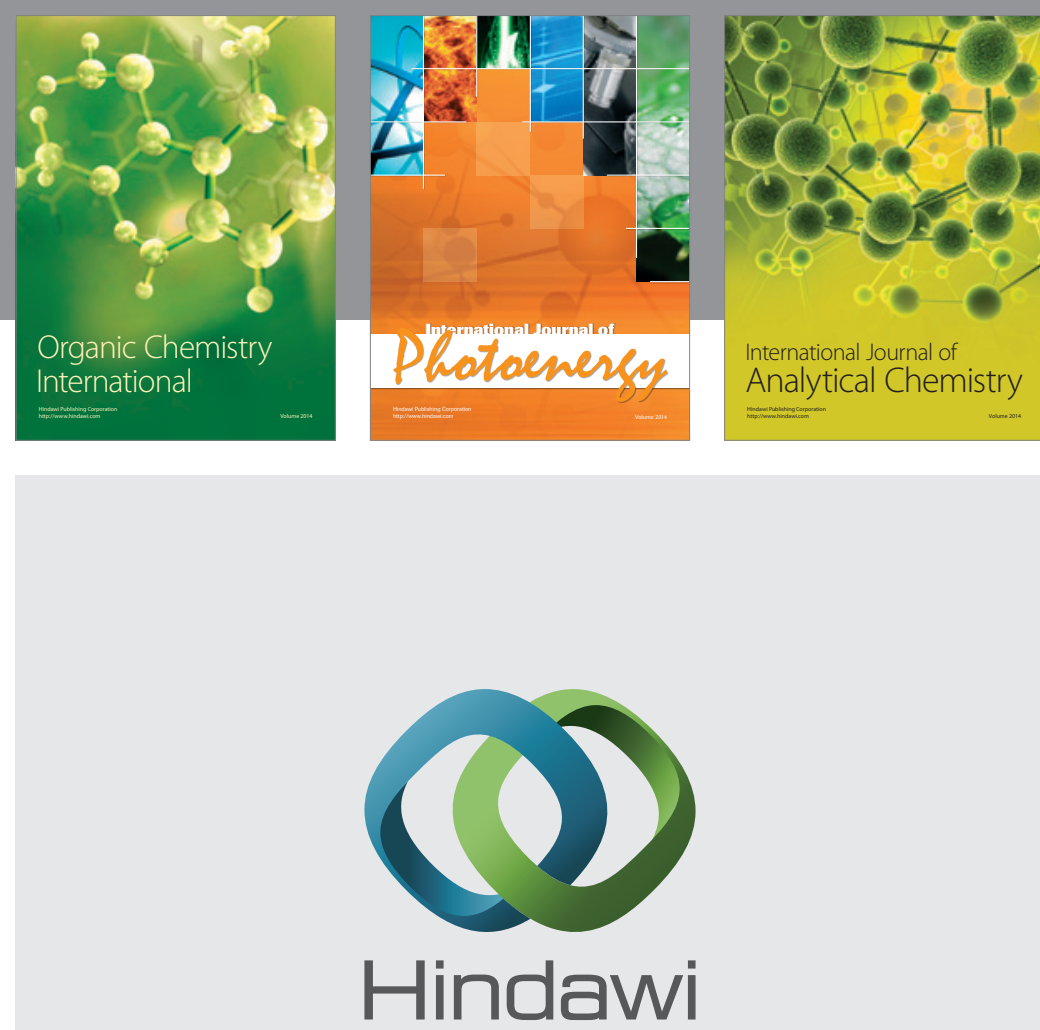

Submit your manuscripts at

http://www.hindawi.com
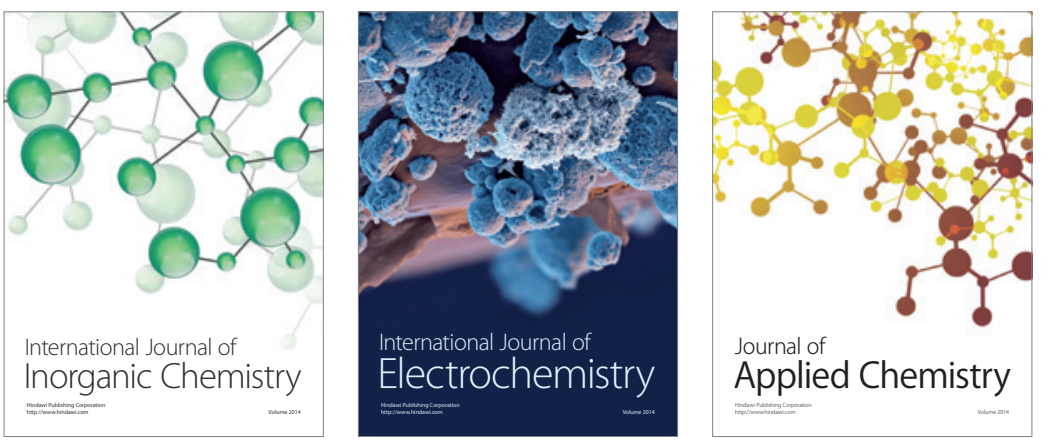

Journal of

Applied Chemistry
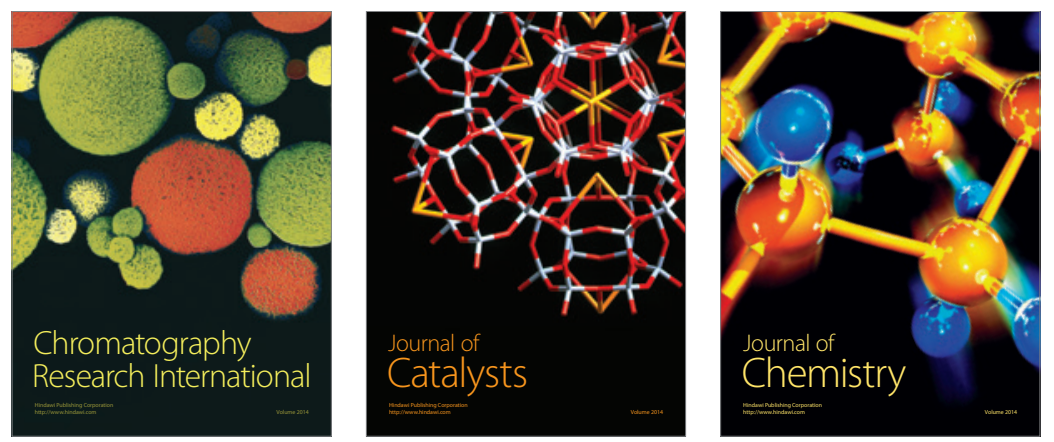
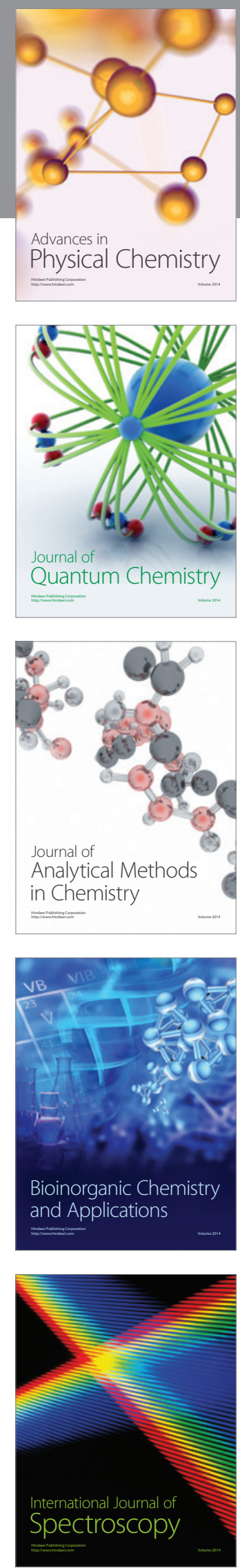